\title{
A Preterm Infant with Hypovolemic Shock: Should Infants be Examined Twice or is Once Enough?
}

\author{
(1) Atef Alshafei, (1) Anwar Khan \\ Dubai Health Authority, Dubai Hospital, Neonatal Intensive Care Unit, Dubai, United Arab Emirates
}

\begin{abstract}
Shock in newborns and preterm infants carries significant morbidity and mortality risks unless there is early recognition and adequate treatment. Signs may only be identified in the late decompensated phase with lactic acidosis, cellular disruption, and irreversible multiorgan damage. In neonates, the etiopathological origin is unique, particularly in extremely preterm infants with a complicated postnatal transition phase, an immature myocardium, and high peripheral systemic resistance. Hypovolemic shock shortly after birth is uncommon and may complicate fetomaternal or fetoplacental transfusion, abruptio placenta, intracranial hemorrhage, or capillary leak syndrome. Without a blood loss history, secondary clinical assessment may reveal the underlying etiology and facilitate targeted interventions.
\end{abstract}

Keywords: Preterm, shock, hypovolemia

\section{Introduction}

An extreme preterm female infant was born via cesarean section at 25 weeks of gestation to a 25 -year-old primigravida woman. The neonate was resuscitated initially with non-invasive Neopuff positive pressure ventilation and eventually by intubation owing to the poor respiratory drive and bradycardia. The Apgar scores were 3 and 7 at 1 minute and 5 minutes, respectively. The infant was born with a birthweight of $710 \mathrm{~g}$ (40 th percentile); a length of $31.5 \mathrm{~cm}$ ( $34^{\text {th }}$ percentile); and an occipitofrontal circumference of $21.6 \mathrm{~cm}$ (17 $7^{\text {th }}$ percentile). On admission, the infant exhibited swelling in the occipital region, which was identified as caput succedaneum; mild hypotonia; and poor tissue perfusion. Cardiovascular examination revealed normal heart sounds and hyperdynamic precordium. The results of abdominal examination were normal, and no organomegaly was noted. Chest examination showed adequate bilateral air entry and mild subcostal recession on mechanical ventilation support.

\section{Case Report}

She was connected to a mechanical ventilator with initial venous blood gas analysis revealing severe metabolic acidosis; $\mathrm{pH}, 7,001 ; \mathrm{pCO}_{2}, 6^{2} \mathrm{mmHg} ; \mathrm{HCO}_{3}, 14.6 \mathrm{mmol} / \mathrm{L}$; base excess, $-14.8 \mathrm{mmol} / \mathrm{L}$; lactic acid, $10.3 \mathrm{mmol} / \mathrm{L}$; hemoglobin, $9.6 \mathrm{~g} / \mathrm{dL}$; glucose, $82 \mathrm{mg} / \mathrm{dL}$; Na, $134 \mathrm{mmol} / \mathrm{L}$; and $\mathrm{K}, 4.8 \mathrm{mmol} / \mathrm{L}$. The infant's heart rate ranged between 150-180 bpm, and oxygen saturation ranged from 85 to $93 \%$ on respiratory support with desaturations, and blood pressure was initially unrecordable. A normal saline bolus was administered, a full sepsis screen was initiated, and the infant was administered ampicillin and gentamicin for presumed sepsis owing to the history of suspected chorioamnionitis. A complete blood cell count revealed a white blood cell (WBC) count of $43,000 / \mu \mathrm{L}$ with $33 \%$ polymorphonuclear leucocytes, 21\% lymphocytes, 6\% monocytes, 5\% band neutrophils, 5\% metamyelocytes, $3 \%$ promyelocytes, $25 \%$ myelocytes, $2 \%$ blast cells, and 43

\section{Address for Correspondence}

Atef Alshafei, Dubai Health Authority, Dubai Hospital, Neonatal Intensive Care Unit, Dubai, United Arab Emirates Phone: +971561924270 E-mail: ahalshafei@dha.gov.ae ORCID: orcid.org/0000-0003-0544-3743 Received: 27.03.2021 Accepted: 20.04.2021

${ }^{(0)}$ Copyright 2021 by Ege University Faculty of Medicine, Department of Pediatrics and Ege Children's Foundation The Journal of Pediatric Research, published by Galenos Publishing House. 
nucleated red blood cells (RBCs) per 100 WBC. A peripheral smear showed anisopoikilocytosis, with normochromic red cells and many nucleated RBCs, neutrophilia with shift to left, and normal platelet count. The Reticulocyte count was $8.2 \%$, and the direct Coombs' test result was negative. The coagulation profile revealed a prolonged prothrombin time and an activated partial thromboplastin time of 17.2 seconds and 110.2 seconds, respectively and an international normalized ratio of 1.6 . The basic metabolic panel was normal. Chest and abdominal radiography showed wellexpanded lung fields and a normally placed umbilical venous catheter. Emergency packed red cell transfusion of $20 \mathrm{~mL} / \mathrm{kg}$ was administered considering the severe anemia, and fresh frozen plasma was administered twice for the deranged coagulation profile. Blood pressure improved shortly after the transfusions to a mean of 27-35 $\mathrm{mmHg}$ without inotropic support, and the level of lactate gradually declined to normal values during the following days. The patient's hemoglobin concentration increased to $13 \mathrm{~g} / \mathrm{dL}$ after blood transfusion the following day. Blood culture results were negative; however, $\mathrm{C}$-reactive protein (CRP) tested positive at $17.4 \mathrm{mg} / \mathrm{L}$ (normal CRP level $<5$ $\mathrm{mg} / \mathrm{L})$. The infant was successfully extubated to noninvasive respiratory support on day 9 of life and a repeated coagulation profile was normal.

\section{Diagnosis}

The low hemoglobin level in the initial blood gas analysis, severe metabolic acidosis, and persistent hypotension alerted the physician to conduct a second clinical assessment to explore signs of possible blood loss. A significant subgaleal hematoma ( $\mathrm{SCH}$ ) was noted in the dependent occipital region of the skull measuring $7 \times 5 \mathrm{~cm}$, which was initially misinterpreted as a caput succedaneum (Figure 1). Brain ultrasonography revealed abundant subgaleal fluid collection with low-level internal echoes and septations measuring at least $5.1 \times 2.6 \times 3.7 \mathrm{~cm}$ and representing a large $\mathrm{SGH}$. Brain parenchyma showed bilateral subependymal hemorrhage and mild periventricular flare (Figure 2).

\section{Discussion}

$\mathrm{SGH}$ is a rare but potentially lethal condition occurring in newborns that typically complicates traumatic delivery, particularly after vacuum extraction or forceps delivery (1). SGH affects approximately 40-60/10,000 deliveries, with a mortality rate of up to $25 \%$ of cases (2). Significant blood loss may accumulate between the skull periosteum and the galea aponeurotica secondary to rupture of emissary veins. This unlimited potential space may contain the whole

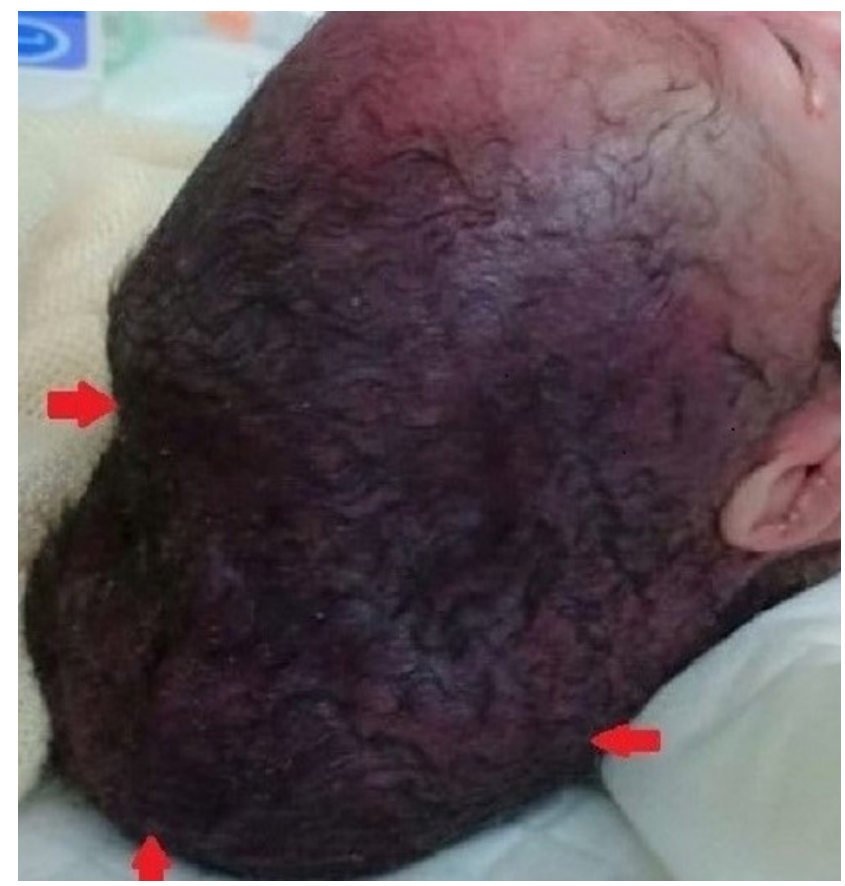

Figure 1. Significant SGH in the dependent occipital region SGH: Subgaleal hematoma

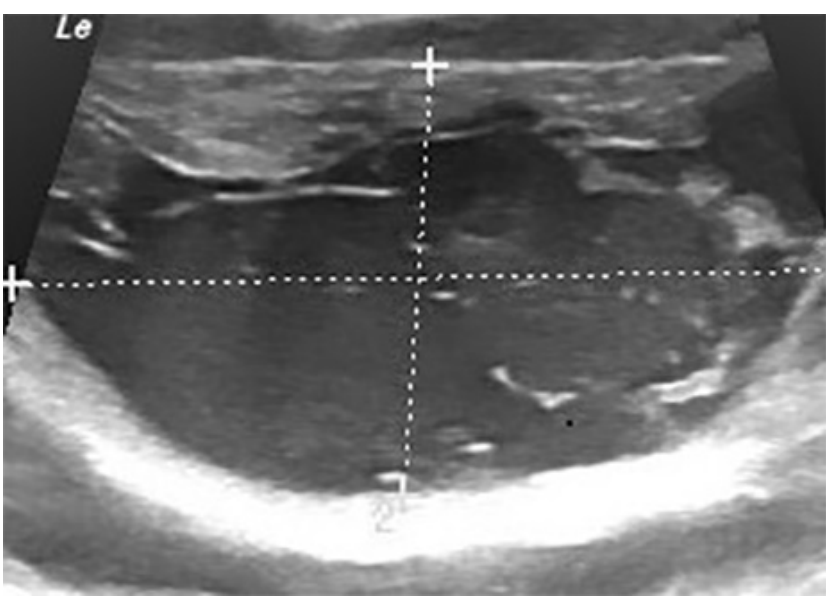

Figure 2. Brain ultrasonography shows large SGH measuring $5.1 \times 2.6 \times 3.7$ $\mathrm{cm}$

SGH: Subgaleal hematoma

blood volume of a neonate and result in hypovolemic shock, coagulopathy, and possible death if not promptly recognized (3). Most of the reported cases in the literature involve term infants and this condition is rarely described in preterm infants. To the best of our knowledge, this is the first case report of SGH affecting an extremely preterm infant at 25 weeks of gestation who had not undergone instrumental delivery. A high index of suspicion is warranted for the diagnosis of SGH very early after birth through meticulous physical examination, as this may be lifesaving. SCH may be overlooked during the initial physical examination, and a 
second clinical assessment is justified in patients presenting with unexplained hypovolemic shock. Typically, severe SGH may initially mimic caput succedaneum but progresses rapidly as a fluctuant boggy mass crossing all sutures and fontanelles, and causing a significant increase in head circumference $(4,5)$. Early recognition of SGH and prompt commencement of management are key to successful short-and long-term outcome. Close observation of vital signs, serial measurements of head circumference, and monitoring of hematocrit and lactate levels are essential in mild to moderate cases of $\mathrm{SGH}(6)$. However, in severe cases presenting with hypovolemic shock, severe anemia, and metabolic acidosis, immediate replacement of volume loss by normal saline boluses, packed RBC transfusions, and possible fresh frozen plasma in cases of coagulopathy are lifesaving (7). A coagulation screen is justified in all cases of $\mathrm{SGH}$, either for diagnostic purposes of a presumed bleeding diathesis as in cases of hemophilia, or for the treatment of the resultant consumption coagulopathy (8). With early recognition and prompt management, the prognosis of $\mathrm{SCH}$ is generally favorable, with a notable recent decrease in mortality rates and long-term morbidities (2).

- SCH may be overlooked on initial neonatal examination and a second clinical assessment is justified after admission of infants with severe anemia and/or unexplained hypovolemic shock and increased lactate level.

- Meticulous monitoring and a high index of suspicion are fundamental for the early recognition of $\mathrm{SGH}$ that occasionally complicates non-instrumental delivery.

- SGH is a potentially lethal but a preventable clinical emergency and prompt aggressive management definitely improves its prognosis.

\section{Ethics}

Informed Consent: The authors certify that they have obtained all appropriate patient consent forms.
Peer-review: Externally peer-reviewed.

\section{Authorship Contributions}

Concept: A.A., A.K., Data Collection or Processing: A.A., A.K., Analysis or Interpretation: A.A., A.K., Literature Search: A.A., A.K., Writing: A.A., A.K.

Conflict of Interest: No conflict of interest was declared by the authors.

Financial Disclosure: The authors declared that this study received no financial support.

\section{References}

1. Swanson AE, Veldman A, Wallace EM, Malhotra A. Subgaleal hemorrhage: risk factors and outcomes. Acta Obstet Gynecol Scand 2012; 91:260-3.

2. Christensen RD, Baer VL, Henry E. Neonatal subgaleal hemorrhage in a multihospital healthcare system: prevalence, associations, and outcomes. e-J Neonatol Res 2011; 1:1-8.

3. Kilani RA, Wetmore J. Neonatal subgaleal hematoma: presentation and outcome--radiological findings and factors associated with mortality. Am / Perinatol 2006; 23:41-8.

4. Ditzenberger G, Blackburn S. Neurologic system. In: Kenner C, Lott I (eds). Comprehensive neonatal nursing care, 5th ed. New York, Springer Publishing Company, 2014; 393-437.

5. Cheong IL, Hagmann C, Rennie JM, et al. Images in neonatal medicine. Fatal newborn head enlargement: high resolution magnetic resonance imaging at $4.7 \mathrm{~T}$. Arch Dis Child Fetal Neonatal Ed 2006; 91:F202-3.

6. Sun JL, Jin K, Sun JK. The clinical characteristics and prognosis of subgaleal hemorrhage in newborn. Korean J Pediatr 2018; 61:387-91.

7. Colditz MJ, Lai MM, Cartwright DW, Colditz PB. Subgaleal haemorrhage in the newborn: a call for early diagnosis and aggressive management. J Paediatr Child Health 2015; 51:140-6.

8. Wetzel EA, Kingma PS. Subgaleal hemorrhage in a neonate with factor $X$ deficiency following a non-traumatic cesarean section. J Perinatol 2012; 32:304-5. 